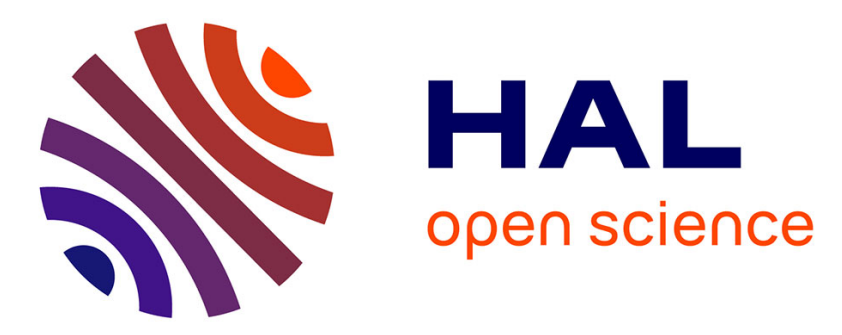

\title{
Heterogeneous oxidation of two triazole pesticides (diniconazole and tebuconazole) by OH-radicals and ozone
}

\author{
O. Rokbani, S. Fattouch, A. Chakir, E. Roth
}

\section{To cite this version:}

O. Rokbani, S. Fattouch, A. Chakir, E. Roth. Heterogeneous oxidation of two triazole pesticides (diniconazole and tebuconazole) by OH-radicals and ozone. Science of the Total Environment, 2019, 694, pp.133745 -. 10.1016/j.scitotenv.2019.133745 . hal-03487216

\section{HAL Id: hal-03487216 \\ https://hal.science/hal-03487216}

Submitted on 20 Dec 2021

HAL is a multi-disciplinary open access archive for the deposit and dissemination of scientific research documents, whether they are published or not. The documents may come from teaching and research institutions in France or abroad, or from public or private research centers.
L'archive ouverte pluridisciplinaire HAL, est destinée au dépôt et à la diffusion de documents scientifiques de niveau recherche, publiés ou non, émanant des établissements d'enseignement et de recherche français ou étrangers, des laboratoires publics ou privés.

\section{(ㄷ)(1) $\$$}

Distributed under a Creative Commons Attribution - NonCommerciall 4.0 International 
1 Heterogeneous oxidation of two triazole pesticides (diniconazole and tebuconazole) by

2

3

4

5

6

7

8

9

\section{OH-radicals and ozone.}

Rokbani, $0 .{ }^{1,2,3}$, Fattouch, S. ${ }^{2}$, Chakir, A. ${ }^{1}$, Roth, E. ${ }^{1 *}$

${ }^{1}$ Université de Reims Champagne Ardenne, CNRS, GSMA, UMR 7331, 51097 Reims, France GSMA, UMR CNRS 7331, Moulin de la Housse, B.P. 1039, 51687 Reims, France;

${ }^{2}$ Food and Molecular Biochemistry Laboratory, National Institute of Applied Sciences Technology (INSAT), University of Carthage, Tunis 1080, Tunisia;

${ }^{3}$ Faculty of Sciences of Bizerte, University of Carthage, Tunis 1080, Tunisia;

*Corresponding author, e-mail : estelle.roth@univ-reims.fr

Phone number : +33-(0)3-26-91-32-31.

\section{Abstract}

Tebuconazole ( $\mathrm{Tbz}$ ) and diniconazole ( $\mathrm{Dnz})$ were deposited as thin film on quartz plaques. They were submitted to $\mathrm{OH}$-radicals and ozone and their kinetic was measured. $\mathrm{OH}$-radical oxidation was performed relative to a reference whose rate constant is well known. Terbuthylazine (Tbt) and Chlorpyriphos Ethyl (Clp) were chosen as reference for Tbz and Dnz kinetics determination, respectively. $\mathrm{OH}$-radical rate constants of $\mathrm{Tbz}$ and $\mathrm{Dnz}$ were found to be: $\mathrm{k}_{\mathrm{OH}+\mathrm{Tbz}}=(1.7 \pm 0.2) 10^{-13} \mathrm{~cm}^{3}$ molecule $^{-1} \mathrm{~s}^{-1}$ and $\mathrm{k}_{\mathrm{OH}+\mathrm{Dnz}}=(1.74 \pm 1.21) 10^{-12} \mathrm{~cm}^{3}$ molecule $\mathrm{e}^{-1}$ 
221 , respectively. Ozone heterogeneous oxidation rate constants were determined in an

23 absolute way: $\mathrm{k}_{03+\mathrm{Tbz}}=(0.5 \pm 0.2) 10^{-20} \mathrm{~cm}^{3}$ molecule ${ }^{-1} \mathrm{~s}^{-1} ; \mathrm{k}_{03+\mathrm{Dnz}}=(1.4 \pm 0.2) 10^{-19} \mathrm{~cm}^{3}$

24 molecule $\mathrm{e}^{-1} \mathrm{~s}^{-1}$

25 Dnz is ten times more reactive towards $\mathrm{OH}$-radicals than $\mathrm{Tbz}$ and 27 times more reactive

26 than Tbz towards ozone maybe because of the presence of a double bond in Dnz. Lifetimes

27 of Tbz and Dnz on quartz like surfaces are against OH-radicals are of 68 days and 8 days,

28 respectively and 4 months and several years against ozone, respectively.

Graphical abstract

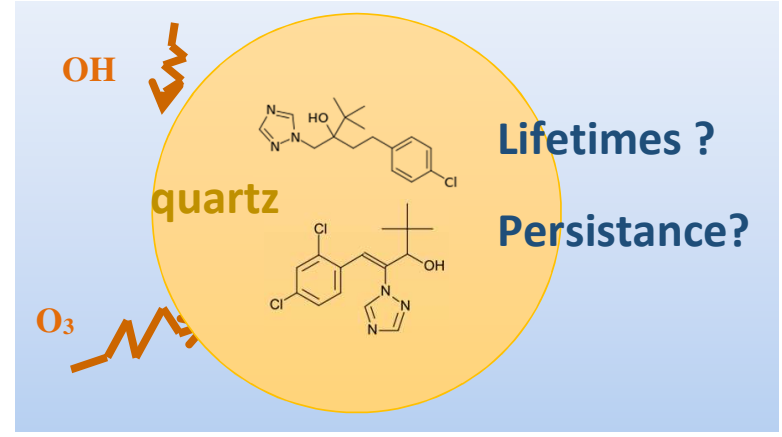

Highlights:

The heterogeneous reaction of $\mathrm{OH}$-radicals with tebuconazole is negligible

37 Tebuconazole on quartz like surfaces is non-reactive toward ozone

Particulate tebuconazole may be submitted to long-range atmospheric transport

Diniconazole is more reactive than Tebuconazole against ozone and $\mathrm{OH}$-radicals

Keywords: pesticide, diniconazole, tebuconazole, OH-radicals, ozone, heterogeneous reaction 


\section{Introduction}

47 When spread on culture, pesticides can reach soil where they can further undergo soil erosion (Cousins et al., 1999) or be released in the atmosphere. Once in the atmosphere, they are distributed in the gaseous, aqueous and particulate phases of the atmosphere according to their physicochemical properties. Because of their low volatility, pesticides can be found in the particulate phase of the atmosphere up to several hundred pg per cube meter (Coscolla et al., 2014). The atmospheric fate of pesticides in particulate phase is influenced by transport processes as well as heterogeneous transformations at the gas/particle interface induced by photo-oxidants. The pesticide lifetime on a particle is thus greatly dependant on its reactivity toward photo-oxidants. Some heterogeneous kinetic measurements toward ozone, $\mathrm{OH}$-radicals and nitrate radicals exist in the literature (Palm et al., 1998; Pflieger et al., 2009, Segal-Rosenheimer et al., 2011; Yang et al., 2011). The heterogeneous reactivity of pesticides toward these oxidant is impacted by the chemical structure, the nature of the surface of the solid support (Mattei et al., 2019; Lester at al. 2017; Segal-Rosenheimer et al., 2011) and the humidity (Mattei et al., 2019; Palm et al., 1997). However existing studies do not provide a full overview of the atmospheric persistence and reactivity regarding to the pesticides' structure and particle nature diversities. To assess the persistence of pesticides on solid/gas interfaces towards atmospheric oxidants, more heterogeneous kinetic measurements are thus necessary. We propose to study the kinetic of heterogeneous degradation of two triazole pesticides tebuconazole ( $\mathrm{Tbz}$ ) and diniconazole ( $\mathrm{Dnz})$ with $\mathrm{OH}$-radicals and ozone and investigate the 
structure-reactivity relations. Since the seventies, triazoles compounds are widely used as broad spectrum fungicides for many crops or biocides in various industrial products like wood preservative. On the market since 1986, Tbz occupies the first position in terms of triazole global sales but is also present in the French National Pesticide List for Pesticides to be assessed in ambient air (Anses, 2010). Meanwhile Dnz was introduced in 1983 but is no longer approved under the EC Regulation 1107/2009.

The structures of Dnz and Tbz are close but differ by the presence of a carbon-carbon double bond and an additional chlorine atom on the aromatic cycle in diniconazole. A vapor pressure of $1.310^{-3} \mathrm{mPa}$ at $25^{\circ} \mathrm{C}$ for tebuconazole (Tbz) suggest that it might exist in the particulate phase in the atmosphere. (Tomlin, 2000). Indeed TBZ was measured up to 8.18 $\mathrm{ng} / \mathrm{m}^{3}$ in the vicinity of maize and cereal crops in gathered particle and gas phase samples (Scheyer et al., 2007). Tbz concentrations of about $32 \pm 8 \mathrm{ng} / \mathrm{m}^{3}$ were detected in total suspended particles (Coscolla et al., 2014): a size distribution profile of tebuconazole concentration showed that Tbz was especially in the fine fraction of the atmospheric aerosol below $1 \mu \mathrm{m}$. More recently, Tbz was detected in air samples gathering gaseous and particle phases in the south of France around $0.01 \mathrm{ng} / \mathrm{m}^{3}$ (Désert et al., 2018). Moreover Tbz has a great affinity with soils and sediments: it was detected at around $0.1 \mu \mathrm{g}$ per $\mathrm{kg}$ lake sediment in northen Greece (Kalogridi et al., 2014). Less studies deals with the spread and persistence of Dnz in the environment. The sunlight photodegradation of diniconazole as a thin film on glass surface showed the formation of aldehydes and ketones (Sharma and Chibber, 1997) within $21 \mathrm{~h}$. Dnz was detected in plants and showed a half-life time around 3 days in tea leaves (Xinzhong et al., 2018). 
89 In terms of atmospheric reactivity, no study was found in the literature for these species.

90 Regarding the presence of Tbz especially in the particulate phase of the atmosphere and

91 knowing that the main components of atmospheric mineral dust include quartz, feldspar,

92 carbonate and clay, we propose to study the heterogeneous oxidation of Tbz and Dnz

93 deposited on quartz plaques with $\mathrm{OH}$-radicals and ozone which are two of the most 94 important atmospheric oxidants. Lifetimes will be deduced from rate constants and 95 compared with gaseous rate constants and heterogeneous rate constant of other pesticides 96 family.

\section{Materials and Methods}

\subsection{Method}

100

2.1.1 OH-radical oxidation

101 The relative method was used to study the kinetics of degradation of target pesticides. This

102 method consists in simultaneously monitoring the temporal evolution concentration of the 103 pesticide (Pest) and a reference compound (Ref). These species are consumed mainly by 104 following reactions:

105 Pest(s) $+\mathrm{OH} \rightarrow$ products $\left(\mathrm{k}_{\mathrm{OH}}\right)$

107 where $\mathrm{k}_{\mathrm{OH}}$ and $\mathrm{k}_{\text {ref }}\left(\mathrm{cm}^{3}\right.$ molecule $\left.\mathrm{e} \mathrm{s}^{-1}\right)$ are the second order rate constants of the 108 heterogeneous reactions between the studied pesticide and the reference, respectively. 
109 Other secondary reactions of first order such as photolysis or volatilization may as well take

110 place leading to pesticide or reference loss:

111 Pest(s) $\rightarrow$ products

$112 \operatorname{Ref}(\mathrm{s}) \rightarrow$ products

$113 k_{p}$ and $k_{p}^{\prime}$ are the sum of the first order rate constants $\left(\mathrm{s}^{-1}\right)$ of secondary reactions consuming 114 the pesticide and the reference, respectively.

115 Kinetic analysis of reactions (1), (2), (3) and (4) leads to the following relation:

$116 \frac{1}{t} \cdot \ln \left(\frac{[\text { Pest }]_{t 0}}{[\text { Pest }]_{t}}\right)=\frac{R}{t} \cdot \ln \left(\frac{[\text { Ref }]_{t 0}}{[\text { Ref }]_{t}}\right)+\left(k_{P}-R \cdot k_{P}^{\prime}\right)$

117 With $R=\frac{k_{P e s t}}{k_{R e f}}$, the ratio between the rate constant of the studied pesticide and the 118 reference toward $\mathrm{OH}$-radicals. [Pest $]_{\mathrm{to}}$ and $[\text { Ref }]_{\mathrm{t}}$ are the initial concentrations of the studied 119 pesticide and the reference pesticide at time $t_{0}$, respectively; [Pest $]_{t}$ and $[\text { ref }]_{t}$ are the 120 concentrations of the studied pesticide and the reference pesticide at time t.

121 According to equation (5), a plot of $\frac{1}{t} \cdot \ln \left(\frac{[\text { Pest }]_{t 0}}{[\text { Pest }]_{t}}\right)$ as a function of $\frac{1}{t} \cdot \ln \left(\frac{[\text { Ref }]_{t 0}}{[\text { Ref }]_{t}}\right)$ results in a

122 linear fit whose slope is equal to $R=\frac{k_{\text {Pest }}}{k_{R e f}}$. Knowing the rate constant between $\mathrm{OH}$ and the 123 reference we can deduce the rate constant between $\mathrm{OH}$-radicals and the studied pesticide.

124 The reference compounds were chosen because their kinetic rate constants, in 125 heterogeneous phase, are well known and were determined in conditions close to ours. 126 Terbuthylazine (Tbt) was selected as the reference to study Tbz. For this reference 127 compound two determinations exist in the literature. Pflieger et al. (2013) have determined 128 a rate constant of $\mathrm{k}_{\mathrm{Tbt}}=(1.5 \pm 0.8) 10^{-13} \mathrm{~cm}^{3}$ molecule $\mathrm{e}^{-1} \mathrm{~s}^{-1}$ for the heterogeneous $\mathrm{OH}$-reaction 
129 of Tbt on hydrophobic silica and relative humidity below 1\%. Meanwhile Palm et al. (1998)

130 have determined a rate constant of $1.110^{-11} \mathrm{~cm}^{3}$ molecule $\mathrm{e}^{-1} \mathrm{~s}^{-1}$ for the heterogeneous $\mathrm{OH}$ -

131 reaction of Tbt on hydrophilic silica at a humidity of $50 \%$. It is known that, humidity has a

132 great influence on the heterogeneous degradation of pesticides by OH-radicals (Mattei et al.,

133 2019). Therefore, in this work it is better to use the value of $\mathrm{OH}$ reactivity of terbuthylazine

134 reported by Pflieger et al. (2013).

135 The reactivity of Dnz toward OH-radicals was study relative to Chlorpyrifos $\left(\mathrm{k}_{\mathrm{Clp}}=(5.8 \pm 4.0)\right.$

$13610^{-12} \mathrm{~cm}^{3}$ molecule $\mathrm{e}^{-1} \mathrm{~s}^{-1}$ ) whose reactivity was studied in the same device by El Masri et al.

137 (2014).

138

$139 \quad$ 2.1.2 Ozonolysis of pesticides

140 The absolute method was used to study the ozonolysis of Tbz and Dnz. Experiment

141 conditions were set so that ozone concentration didn't vary more than $10 \%$ during an

142 experiment (Table 1). In such conditions, the pesticide's concentration decay can be

143 modelled by a pseudo first order kinetic:

$$
\frac{[\text { Pest }]_{t}}{[\text { Pest }]_{t 0}}=\exp \left(-k_{\text {app }} \cdot t\right)
$$

145 where $[\text { Pest }]_{\text {to }}$ and $[\text { Pest }]_{t}$ are the initial pesticide concentration at $t_{0}$ and the pesticide 146 concentration at time $t$, respectively. $k_{a p p}\left(s^{-1}\right)$ is the sum of first order or pseudo first order

147 rate constants of pesticide degradation pathways including volatilization. $k_{\text {app }}$ was obtained

148 from the linearization of equation (6) as the slope of the plot of $\ln \left([\mathrm{P}]_{\mathrm{t} 0} /[\mathrm{P}]\right)$ as a function of 149 time. 
150 Once kapp were determined using (6) for different ozone concentration (Table 1), the gas

151 immediate surface reaction (GSR) model or Eley Rideal model was used to analyze kapp.

152 This model states that gaseous ozone reacts with the solid pesticide with a rate constant k03:

$$
\text { Pest }+\mathrm{O}_{3(\mathrm{~g})} \rightarrow \text { products } \quad\left(\mathrm{k}_{\mathrm{O} 3}\right)
$$

154 This equation results in the following kinetic law :

$$
\frac{d[\text { Pest }]}{d t}=k_{O 3} \cdot[\text { Pest }] \cdot\left[O_{3(g)}\right]+k_{0} \cdot[\text { Pest }]=k_{a p p} \cdot[\text { Pest }]
$$

156 Where $k_{a p p}$ is the apparent first order rate of pesticide removal during the experiment. $k_{a p p}$ is

157 the sum of the product of the gaseous ozone concentration and the second order rate 158 constant of $\mathrm{O}_{3}$ with the pesticide and the first order rate constant resulting from other first 159 order phenomena removing the pesticide mainly the volatilization:

$$
k_{a p p}=k_{O 3} \cdot\left[O_{3(g)}\right] \cdot+k_{0}
$$

161 The plot of $k_{a p p}$ as a function of $\left[\mathrm{O}_{3(\mathrm{~g})}\right]$ results in a straight line where $\mathrm{k}_{03}$ is the slope and $\mathrm{k}_{0}$ 162 the intercept.

165 The lifetime of pesticides against an oxidant can be deduced from the rate constant by 166 calculating their lifetime against the oxidant, $\tau_{\mathrm{x}}$ :

$$
\tau_{X}=\frac{1}{k_{X} \cdot[X]}
$$


168 Where $[\mathrm{X}]$ is the average oxidant concentration or ozone in the atmosphere and $k x$ the rate 169 coefficient of the pesticide reaction with the oxidant $X$.

\section{0 \\ 2.2 Experimental procedure}

171 The experimental procedure has been depicted in a previous study in detail (Rashidi et al., 172 2011). Thus, it will only be described briefly herein. Experiments were performed in a one 173 meter long Pyrex cell with a diameter of $5 \mathrm{~cm}$. Quartz windows closed both extremities of 174 the cell to allow a UV beam issued from a deuterium lamp to pass through it. Beam was 175 focalized on an Avaspec CCD camera (Avantes) to be analyzed. The pressure of the reaction 176 mixture inside the reactor was measured by a pressure sensor (0 - 1000 mbar MKS Baratron 177 capacitance). Two platinum resistance sensors, positioned at each cell extremities, were 178 used to measure the reaction temperature. Experiments were performed at $25 \pm 2{ }^{\circ} \mathrm{C}$ in the 179 case of $\mathrm{OH}$-oxidation and at $20 \pm 2{ }^{\circ} \mathrm{C}$ in the case of the oxidation by ozone.

Pesticide coated plaques were prepared by transferring $1 \mathrm{~mL}$ of $1 \mathrm{mg} \mathrm{L}^{-1}$ of standard pesticide solution (Pestanal ${ }^{\circledR}$, Sigma-Aldrich) in dichloromethane in $6 \times 3 \times 1(L x / x h) \mathrm{cm}^{3}$ quartz plaques. Pesticide coated plaques with $1 \mu \mathrm{g}$ of pesticide were obtained after evaporation of the solvent. The surface coverage of quartz plaques were $82 \%, 72 \%, 63 \%$ and $84 \%$ for Tbz, Dnz, Clp and Tbt, respectively. Pesticides were all quality from Sigma Aldrich.

- Ozonolysis experiments: Eight pesticide coated plaques were initially placed in the reaction. Ozone was produced in an ozonizer using an oxygen flow. The mixture ozone/oxygen was completed with air to reach $400 \pm 50$ Torr and swept in the reactor. According to Beer Lambert's law, ozone concentration in the reactor was measured at $254 \mathrm{~nm}$ and $270 \mathrm{~nm}$ where $\sigma^{254}{ }_{\mathrm{O} 3}=1.1310^{-17} \mathrm{~cm}^{2}$ molecule ${ }^{-1}$ and $\sigma^{270}{ }_{03}=$ 
determined exposure time, the reactor was emptied from ozone, and open to remove a plaque. Remaining plaques were then again exposed to same ozone concentration. The average ozone concentration did not vary more than $10 \%$ (Table 2). For one ozone concertation, 8 to 16 measures at different time were performed resulting in the determination of one apparent constant plotted in figure 1.

- Oxidation by $\mathrm{OH}$-radicals: The reactor was initially filled with 4 plaques coated with the studied pesticide and 4 plaques coated with the reference. OH-radicals were obtained by the photolysis of HONO. HONO was produced by adding drops of a sulphuric acid solution (10\%) to a nitrite sodium solution $(0.2 \mathrm{M})$ and carried into the reactor by a slight flow of synthetic air. Pressure was adjusted between 300 and 400 Torr with synthetic air. The concentration of the $\mathrm{OH}$-radicals precursor, HONO was measured optically at $354 \mathrm{~nm}$ using the Beer-Lambert with $\sigma_{\text {HONO }}=4.8710^{-19} \mathrm{~cm}^{2}$ molecule ${ }^{-1}$ (Sanders et al., 2006). The concentration of HONO was varied between (1 to 7) $10^{16}$ molecule $\mathrm{cm}^{-3}$. Lamps were switched on to begin the reaction. At increasing time, the reactor was emptied, open and one plaque of the pesticide and one of the reference were systematically removed together. More than 45 measures for the studied pesticide and for the reference were performed. Each point on Figure 2 and 3 represent the average of 2 to 3 independent measures.

Once removed from the reactor, plaques were extracted 3 times with $0.5 \mathrm{~mL}$ of 210 dichloromethane by manual shaking for a final volume of $2 \mathrm{~mL}$. Extraction recovery were 211 over $95 \%$ for the 4 pesticides. Extracts were analysed by gas chromatography (GC) coupled 212 to a mass spectrometer (Thermo Fisher TraceUltra DSQII) in the positive electron ionization 213 mode using the selective ion monitoring (SIM) mode. Helium (ALPHAGAZ 2 provided by Air 
214 Liquid) was used as a carrier gas at a constant flow rate of $1.2 \mathrm{~mL} \mathrm{~min}^{-1}$. GC/MS analytical

215 parameters and analysis conditions are summarized in Table 1S (supplementary file).

\section{Results and discussion}

\subsection{Pesticides ozonolysis}

Ozonolysis experiments of both pesticides were performed at different ozone concentrations. The first order apparent rate constants $k_{a p p}$ were determined from the fit of equation (9). The error on $k_{a p p}$ was set at 2 times the statistical error given by the software Origin Pro. Values of $k_{a p p}$ for Tbz and Dnz at different ozone concentrations are gathered in

\section{Table 1.}

Table 1: $k_{a p p}$ measurements for different ozone concentrations and related k03

\begin{tabular}{|c|c|c|c|}
\hline & {$\left[\mathrm{O}_{3(\mathrm{~g})}\right]$ (molecule $\mathrm{cm}^{-3}$ ) } & $k_{\text {app }}\left(s^{-1}\right)$ & $\mathrm{k}_{\text {03 }}\left(\mathrm{cm}^{3}\right.$ molecule $\left.^{-1} \mathrm{~s}^{-1}\right)$ \\
\hline \multirow[t]{4}{*}{ TBZ } & $(1.8 \pm 0.2) 10^{15}$ & $(0.9 \pm 0.1) 10^{-5}$ & \multirow{4}{*}{$(0.5 \pm 0.2) 10^{-20}$} \\
\hline & $(2.5 \pm 0.2) 10^{15}$ & $(1.2 \pm 0.1) 10^{-5}$ & \\
\hline & $(3.1 \pm 0.2) 10^{15}$ & $(1.6 \pm 0.2) 10^{-5}$ & \\
\hline & $(4.1 \pm 0.3) 10^{15}$ & $(2.2 \pm 0.2) 10^{-5}$ & \\
\hline \multirow[t]{4}{*}{ DNZ } & $(1.5 \pm 0.1) 10^{15}$ & $(1.9 \pm 0.1) 10^{-4}$ & \multirow{4}{*}{$(1.4 \pm 0.2) 10^{-19}$} \\
\hline & $(2.0 \pm 0.2) 10^{15}$ & $(3.1 \pm 0.3) 10^{-4}$ & \\
\hline & $(2.9 \pm 0.2) 10^{15}$ & $(4.5 \pm 0.4) 10^{-4}$ & \\
\hline & $(4.4 \pm 0.4) 10^{15}$ & $(5.9 \pm 0.5) 10^{-4}$ & \\
\hline
\end{tabular}




\begin{tabular}{|l|l|l|l|}
\hline & $(7.0 \pm 0.6) 10^{15}$ & $(9.7 \pm 0.4) 10^{-4}$ & \\
\hline
\end{tabular}

227 The gas surface reaction model was used to analyze ozonolysis results. Plots of $k_{a p p}$ as a

228 function of the ozone concentration in the reactor, measured by UV spectroscopy, result in a

229 straight line passing through the origin for both pesticides confirming that no volatilization of

230 pesticide occurs due to the opening of the reactor during an experiment (Figure 1). As a

231 matter of fact, experiments without any introduction of oxidant and with all the

232 manipulations of plaques and the gas flow mixtures/pression adjustments showed that TBZ

233 and DNZ do not volatilize during experiments as awaited from their low vapor pressure

234 values. Thus the pesticide decrease along time was only due to its reaction with ozone. The

235 rate constant of the heterogeneous ozonolysis corresponds to the slope of the plots on

236 Figure 1: $\mathrm{k}_{\mathrm{O} 3+\mathrm{Tbz}}=(0.5 \pm 0.2) 10^{-20} \mathrm{~cm}^{3}$ molecule $^{-1} \mathrm{~s}^{-1} ; \mathrm{k}_{\mathrm{O} 3+\mathrm{Dnz}}=(1.4 \pm 0.2) 10^{-19} \mathrm{~cm}^{3} \mathrm{molecule}^{-1} \mathrm{~s}^{-}$

2371.

238

239

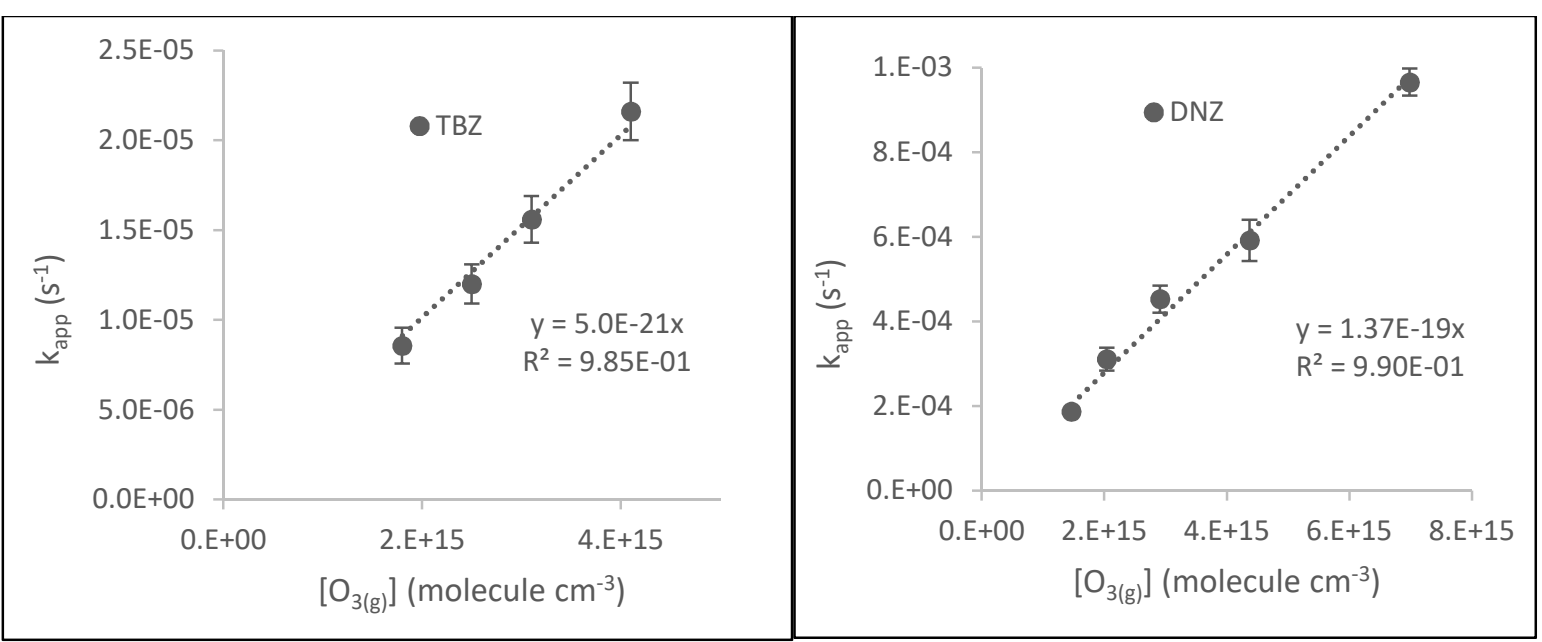

241 Figure 1: Plot of $k_{a p p}$ as a function of ozone concentration for Tbz and Dnz 
243 Uncertainties on the rate constant between the pesticide and ozone are two times the 244 standard deviation calculated with the weighted error method with Origin Pro. With a rate 245 coefficient lower than $10^{-20} \mathrm{~cm}^{3}$ molecule $\mathrm{e}^{-1} \mathrm{~s}^{-1} \mathrm{Tbz}$ can be considered as non-reactive toward 246 ozone. As expected, Dnz is more reactive than Tbz towards ozone probably due to the 247 double bond.

\subsection{Pesticides reaction with OH-radicals}

250

Rate constant of Tbz and Dnz deposited on quartz plaques against $\mathrm{OH}$-radicals were

251 determined relative to Tbt and Clp, respectively. Figures 2 and 3 show the plot of $\frac{1}{t}$.

$252 \ln \left(\frac{[\text { Pest }]_{t 0}}{[\text { Pest }]_{t}}\right)$ as a function of $\frac{1}{t} \cdot \ln \left(\frac{[\text { Ref }]_{t 0}}{[\text { Ref }]_{t}}\right)$ for Tbz and Dnz associated to their corresponding 253 reference. As expected from equation (9), a good linear plot is observed with a correlation 254 coefficient greater than $95 \%$ in Figure 2. Meanwhile, in figure 3, points are relatively 255 dispersed, and the linear plot is obtained with a correlation coefficient of 0.7 . 


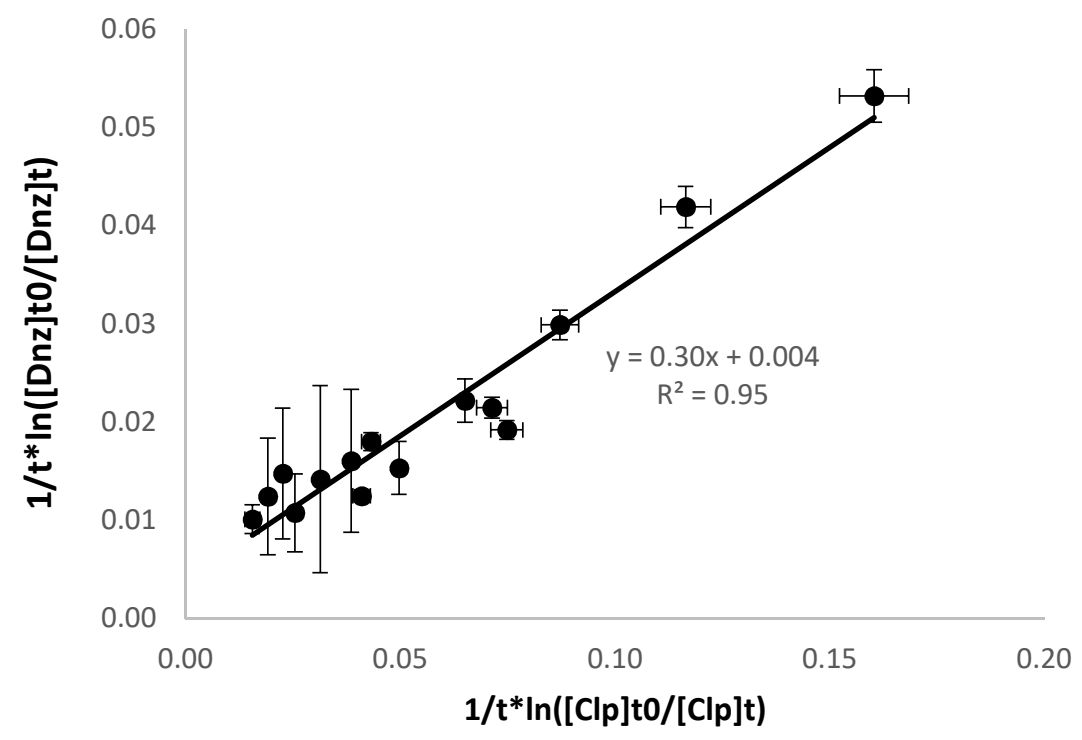

Figure 2: Plot of $\ln \left([D n z]_{t 0} /[D n z]_{t}\right) / t$ as a function of $\ln \left([C \mid p]_{t o} /[C l p]_{t}\right) / t$

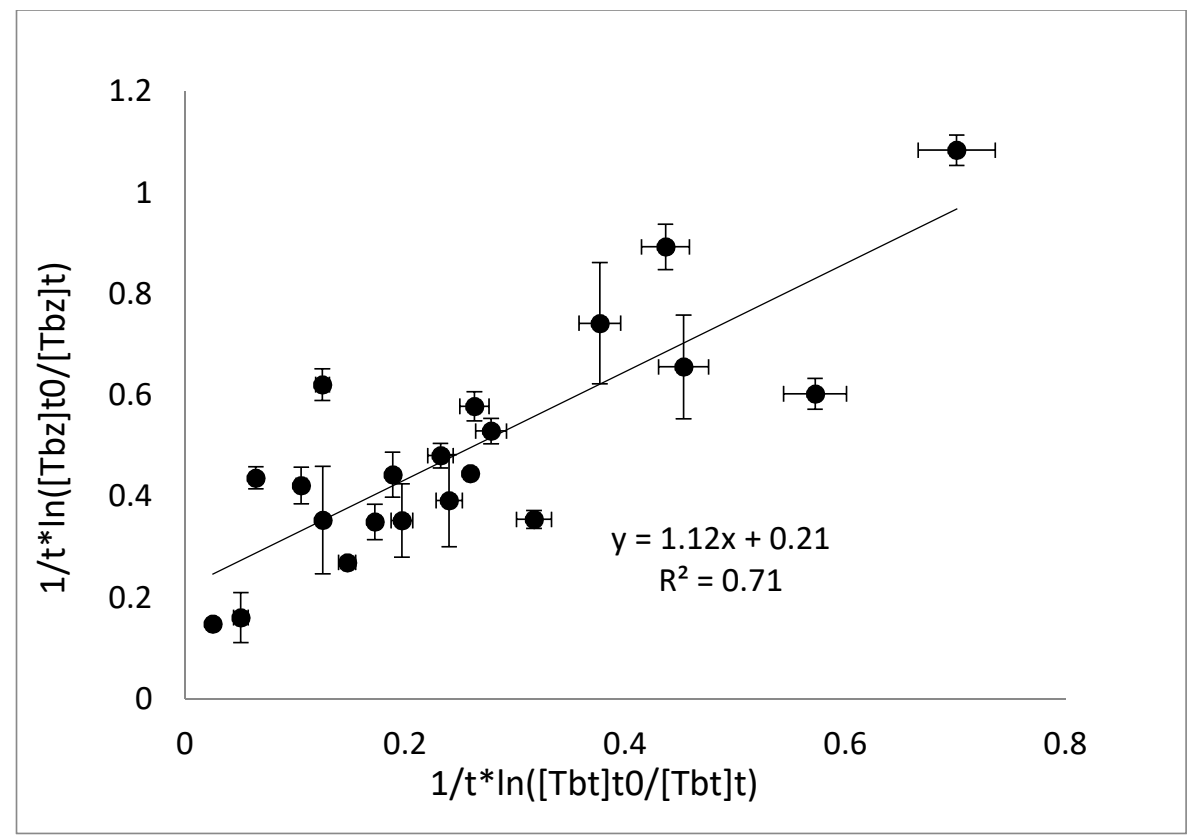

Figure 3: Plot of $\ln \left([\mathrm{Tbz}]_{\mathrm{t} 0} /[\mathrm{Tbz}]_{\mathrm{t}}\right) / \mathrm{t}$ as a function of $\ln \left([\mathrm{Tbt}]_{\mathrm{t} 0} /[\mathrm{Tbt}]_{\mathrm{t}}\right) / \mathrm{t}$ 
263 A linear fit of data on Figure 2 and 3 gives slopes $R=0.30 \pm 0.03$ and $R=1.12 \pm 0.16$ for Dnz and

264 Tbz, respectively. Uncertainties were calculated by the weighted method using OriginPro.

265 The rate constant between $\mathrm{Dnz}$ and $\mathrm{Tbz}$ and $\mathrm{OH}$-radicals were deduced from the relation

$266 R=\frac{k_{P e s t}}{k_{R e f}}$

$267 \mathrm{k}_{\mathrm{OH}+\mathrm{Tbz}}=(1.70 \pm 0.93) 10^{-13} \mathrm{~cm}^{3}$ molecule $^{-1} \mathrm{~s}^{-1} ; \mathrm{k}_{\mathrm{OH}+\mathrm{Dnz}}=(1.8 \pm 1.3) 10^{-12} \mathrm{~cm}^{3}$ molecule $\mathrm{m}^{-1}$.

268 Errors were determined using the propagation of errors:

$269 \Delta k_{\text {Pest }}=k_{\text {Pest }} \cdot \sqrt{\left(\frac{\Delta R}{R}\right)^{2}+\left(\frac{\Delta k_{R e f}}{k_{R e f}}\right)^{2}}$

270 Where $k_{\text {Ref, }} \Delta \mathrm{k}_{\text {Ref }}$ are the reference rate coefficient and its uncertainty respectively; $\Delta \mathrm{R}$ is the

271 uncertainty of $\mathrm{R}=\mathrm{k}_{\mathrm{Pes}} / \mathrm{k}_{\text {Ref }}$.

272 Errors on rate constants are 56\% for Tbz and 76\% for Dnz. According to the relation (10) the

273 error on the rate coefficient is mainly impacted by the uncertainty of $k_{\text {ref. }}$ This error is

274 relatively large, about $53 \%$ for the reference, Tbt, and about $69 \%$ for the reference Clp. The

275 uncertainty on the ratio $R$ is influenced by the measure of the concentrations of the

276 pesticide and the reference compound. Chromatographic analysis of each sample was

277 repeated 2 to 3 times to control the reproducibility of the results. Errors in GC-MS

278 concentration measurements for Dnz and Tbz didn't vary more than $5 \%$.

$280 \quad 3.3 \quad$ Reactivity trend

281 Table 2 summarizes and compares the rate constants obtained in this work and those of 282 other pesticides. 
OH-Reaction: Heterogeneous rate constants of pesticides toward $\mathrm{OH}$-radicals range between $7.110^{-14}$ to $1.810^{-12} \mathrm{~cm}^{3}$ molecule ${ }^{-1} \mathrm{~s}^{-1}$. Dnz is the more reactive triazole compound.

285

Tbz is ten times less reactive than Dnz. According to the chemical structure of Tbz, the reaction between $\mathrm{Tbz}$ and $\mathrm{OH}$-radicals is expected to proceed via several pathways including the addition to the aromatic $\mathrm{C}_{6}$-cycle or to the $\mathrm{C}_{5}$ aromatic $\mathrm{N}$-heterocycle and $\mathrm{H}$-abstraction processes from different sites. However, without mechanistic studies, it is difficult to identify the most favorable site. Dnz can undergo the same mechanism than Tbz and an addition to its olefinic bond. The fact that $\mathrm{Dnz}$ is ten times more reactive toward $\mathrm{OH}$-radicals than $\mathrm{Tbz}$ when deposited on a quartz plaque is thus an indication that the dominant pathway proceeds mainly via addition to the olefinic bond in the case of Dnz.

Overall rate constants against $\mathrm{OH}$-radicals of $\mathrm{Dnz}$ and $\mathrm{Tbz}$ in gas phase were calculated with the SAR method using AOPWIN v1.92 (Meylan and Howard, 1993; Kwock and Atkinson, 1995). The estimated gas phase rate constant values are $11.510^{-12}$ molecule $\mathrm{cm}^{-3} \mathrm{~s}^{-1}$ and 96 $10^{-12}$ molecule $\mathrm{cm}^{-3} \mathrm{~s}^{-1}$ for the rate constant of the reaction of gaseous Tbz and Dnz with $\mathrm{OH}$ radicals, respectively. These values are 100 times higher than heterogeneous rate constants determined in this work. This shows that the use of quartz as a solid support has an inhibitory effect on the reaction between $\mathrm{OH}$-radicals and pesticides probably by steric hindrance. Such a difference between gaseous and heterogeneous rate constants has already been highlighted in other studies (Pflieger et al., 2013; El Masri et al., 2014; Al Rashidi et al., 2014, Socorro et al., 2016; Lester et al., 2017).

To the best of our knowledge, only two pesticides of the azole pesticide family, difenoconazole and tetraconazole, have been studied in terms of reactivity toward $\mathrm{OH}$ radicals under experimental conditions similar to those of this study (Table 2) (Al Rashidi et al., 2011; Mattei et al., 2019). They both present a lower reactivity against $\mathrm{OH}$-radicals than 
Tbz showing that the chemical structure largely impacts the kinetics of the reaction between

308 the pesticide and $\mathrm{OH}$-radicals. Their structure contains less alkyl groups than Tbz, maybe 309 explaining the lower reactivity of difenoconazole and tetraconazole in comparison to Tbz.

310 Tebuconazole and Terbuthylazine differ mainly by the presence of a $\mathrm{C}_{5}-\mathrm{N}$ heterocycle in 311 tebuconazole and a C6-aromatic group and a $\mathrm{C}_{6}-\mathrm{N}$ heterocycle and amine groups in 312 terbuthylazine. Recent experimental studies on the reactivity of $\mathrm{C}_{5}$ and $\mathrm{C}_{6} \mathrm{~N}$-heterocyclic 313 compounds toward $\mathrm{OH}$-radicals in gas phase showed that $\mathrm{C}_{5}$ heterocyclic compounds were 314 largely more reactive than $C_{6}$ heterocyclic compounds and $C_{6}$ aromatic group (Samir, 2018). 315 Nevertheless, Tbz and Tbt present the same reactivity indicating thus that their reactivity 316 might be governed by the alkyl or amine $\mathrm{H}$ abstraction in the heterogeneous phase.

317 Clp belongs to the family of organophosphorus compounds and contains a $\mathrm{P}=\mathrm{S}$ double bond 318 which is very sensitive to $\mathrm{OH}$ oxidation (El Masri et al., 2014, Munoz et al., 2014) : Clp is 3 319 times more reactive to $\mathrm{OH}$-radicals than Dnz probably due to the presence of this functional 320 group.

322 Table 2: Summary of heterogeneous $\mathrm{OH}$-oxidation rate constants for investigated 323 compounds in this study as well as for other pesticides from the literature.

\begin{tabular}{|c|c|c|c|c|}
\hline Compound & Formula & substrate & $\begin{array}{c}\text { ko3 } \\
\mathrm{cm}^{3} \text { molecule }^{-1} \mathrm{~s}^{-1}\end{array}$ & $\begin{array}{c}\text { koн } \\
\mathrm{cm}^{3} \text { molecule }^{-1} \mathrm{~s}^{-1}\end{array}$ \\
\hline \multirow{2}{*}{ Tebuconazole } & & $\begin{array}{l}\text { Quartz } \\
\text { plaques }\end{array}$ & $\begin{array}{c}(5.1 \pm 0.5) 10^{-21} \\
\text { This work }\end{array}$ & $\begin{array}{c}(1.70 \pm 0.93) 10^{-13} \\
\text { This work }\end{array}$ \\
\hline & & Gas phase & & $\begin{array}{l}11.510^{-12} \\
\text { AOPWIN }\end{array}$ \\
\hline
\end{tabular}




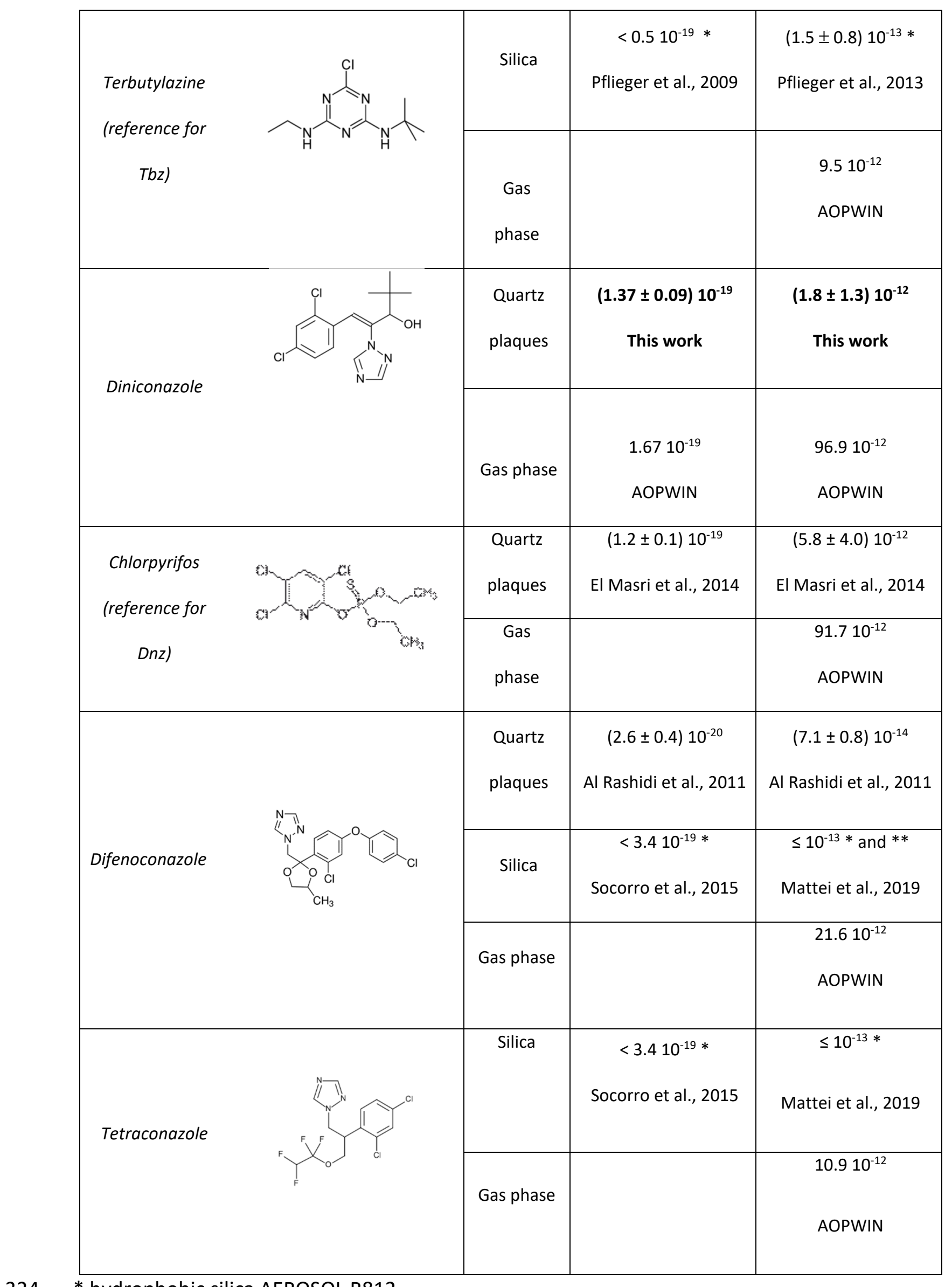


** hydrophilic silica AEROSIL 255

Ozonolysis reaction:

328 Heterogeneous rate constants of pesticides summarized in Table 2 range between $5.110^{-21}$ 329 and $1.3710^{-19} \mathrm{~cm}^{3}$ molecule $\mathrm{s}^{-1}$ ie over more than one range order (Table 3). The 330 comparison of the kinetic coefficients of the ozone reaction with the triazole family 331 pesticides shows that $\mathrm{Dnz}$ is the most reactive towards ozone. This can be explained by the 332 presence of the olefinic bond. Unsaturated chemical bonds are known to be subjected to 333 form an ozonide by addition of ozone which quickly dissociates into an aldehyde and a 334 ketone (Grosjean et al., 1996). Unfortunately, we didn't observed the formation of products 335 maybe due to the lack of sensitivity of our analytical technic. Dimethomorph, which contains 336 also a double bond, has a heterogeneous rate constant towards ozone in conditions similar 337 to ours in the same range order (Al Rashidi et al., 2013). Moreover, Tbz is 5 times less 338 reactive toward ozone than Difenoconazole. Difenoconazole includes one more aromatic 339 cycle than Tbz presenting more double bonds on which ozone can add to form an ozonide.

\subsection{Atmospheric implication}

343 The tropospheric lifetimes of pesticides relative to reactions with both oxidants were 344 estimated according to equation (10). Lifetimes were calculated using the rate constants 345 obtained in this work. A $24 \mathrm{~h}$ daytime average global tropospheric $\mathrm{OH}$ concentration of $1 \times 10^{6}$ 346 molecule $\mathrm{cm}^{-3}$ and an ozone concentration of $40 \mathrm{ppb}$ corresponding to $710^{11}$ molecules $\mathrm{cm}^{-3}$ 347 were used (Atkinson et al., 1997; Vingarzan et al., 2004) (Table 3). Tbz on quartz like surfaces 
348 is more persistent toward OH-radicals and ozone than Dnz (Table 3). Lifetime of Dnz against

349 ozone is several months in comparison to one week against $\mathrm{OH}$-radicals. $\mathrm{Tbz}$ is more 350 persistent in the atmospheric aerosol explaining that it can be detected in atmospheric 351 particles (Scheyer et al., 2007; Hart et al. 2012; Coscolla et al., 2013; Coscolla et al., 2014).

352

353 Table 3: Lifetimes of Tebuconazole and Diniconazole regarding OH-radicals and ozone

\begin{tabular}{cccc}
\hline Compound & & $\tau_{\mathrm{OH}}{ }^{*}$ & $\tau_{03}{ }^{* *}$ \\
& & & \\
Tebuconazole & & Quartz plaques & \\
& & & \\
& & & (9 days years) \\
\hline Diniconazole & Quartz plaques & 8 days & 4 months
\end{tabular}

$354{ }^{*}$ calculated for $[\mathrm{OH}]=10^{6}$ molecules $\mathrm{cm}^{-3}$

$355 * *$ calculated for $\left[\mathrm{O}_{3}\right]=710^{11}$ molecules $\mathrm{cm}^{-3}$

359 . The rate constant between two atmospheric oxidants ( $\mathrm{OH}$-radicals and ozone) and these 360 two pesticides (Tebuconazole and Diniconazole) deposited on quartz plaques were 361 determined. Diniconazole is found to be 10 times more reactive toward $\mathrm{OH}$-radicals than 362 Tebuconazole. Their lifetimes toward $\mathrm{OH}$-radicals are around 2 months and 1 week for 363 Tebuconazole and Diniconazole, respectively. Tebuconazole is non-reactive toward ozone. 364 Diniconazole is resistant to oxidation by ozone with a lifetime of about 4 months. Even if Tbz 365 is more persistent than Dnz toward the two major atmospheric oxidants, the use of Tbz is 
366 still allowed and raise the concern of transborder redeposition and long range

367 contamination of the Atmosphere. For a more accurate lifetime assessment and better 368 understanding of the environment fate, heterogeneous phase reaction with other 369 atmospheric oxidants $\left(\mathrm{NO}_{3}, \mathrm{Cl}\right)$ should be carried out.

370

371

372

373 Acknowledgements

374 The authors would like to acknowledge the PHC Maghreb (15MAG10) program for financing this study.

375

376 


\section{References}

379 ANSES (2010) Recommandations et perspectives pour une surveillance nationale de la 380 contamination de l'air par les pesticides. Synthèse et recommandations du comité 381 d'orientation et de prospective scientifique de l'observatoire des résidus de pesticides (ORP), 382 .Rapport scientifique. photo-oxidation of difenoconazole in the atmosphere. Atmos. Environ. 45, 5997-6003.

Al Rashidi, M., Chakir, A., and Roth, E., 2014. Heterogeneous oxidation of folpet and dimethomorph by $\mathrm{OH}$ radicals: A kinetic and mechanistic study. Atmos. Environ. 82, 164389 171.

390

391 Atkinson, R., Gas-phase tropospheric chemistry of volatile organic compounds: 1. alkanes 392 and alkenesJ. Phys. Chem. Ref. Data, 1997, 26, 215-290.

393

394 Brion, J.; Chakir, A.; Charbonnier, J.; Daumont, D.; Parisse, C.; Malicet, J. Absorption Spectra 395 Measurements for the Ozone Molecule in the 350-830 nm Region. J. Atmos. Chem. 1998, $39630,291-299$. 
398 Coscollà, C., Munoz, A, Borras, E., Vera, T., Rodenas, M., Yusà, V. (2014). Particle size 399 distributions of currently used pesticides in ambient air of an agricultural Mediterranean 400 area, 95. http://doi.org/10.1016/j.atmosenv.2014.06.022

401

402

Cousins, I., Beck, A. J., Jones, K., C., 1999. A review of the processes involved in the exchange 403 of semi-volatile organic compounds (SVOC) across the air-soil interface. Sci. Total Environ.

404 228, 5-24.

405

406

Désert, M., Ravier, S., Gille, G., Quinapallo, A., Armengaud, A., Pochet, G., Savelli, J.-L.,

407 Wortham, H., Quivet, E., 2018. Spatial and temporal distribution of current-use pesticides in 408 ambient air of Provence-Alpes-Côte-d'Azur Region and Corsica, France.

409 Atmos. Environ. 192, 241-256. https://doi.org/10.1016/j.atmosenv.2018.08.054

410

El Masri A., Al Rashidi M., Laversin H., Chakir A., Roth E., 2014. A mechanistic and kinetic 412 study of the heterogeneous degradation of chlorpyrifos and chlorpyrifos oxon under the influence of atmospheric oxidants: ozone and OH-radicals, RSC Advances, 4, 24786-24795.

Grosjean, E.; de Andrade, J. B.; Grosjean, D. Carbonyl Products of the Gas-Phase Reaction of 
423 Kwok and Atkinson, 1995. Estimation of hydroxyl radical reaction rate constants for gas424 phase organic compounds using a structure-reactivity relationship: An update. Atmos. 425 Environ., 29, 1685-1695.

427 Lester, Y., Sabach, S., Zivan, O., Dubowski, Y., 2017. Key environmental processes affecting 428 the fate of the insecticide chloropyrifos applied to leaves. Chemosphere 171, 74-80.

429 https://doi.org/10.1016/j.chemosphere.2016.12.013

430

431 Malicet, J., Daumont, D., Charbonnier, J., Parisse, C., Chakir, A., Brion, J. (1995) Ozone UV 432 spectroscopy. II. Absorption cross sections and temperature dependence, Journal of 433 Atmospheric Chemistry, 21, 263-273.

434

435 Mattei, C.,Wortham, H., Quivet, E., 2018. Heterogeneous atmospheric degradation of 436 pesticides by ozone: influence of relative humidity and particle type. Sci. Total Environ. 625, $437 \quad 1544-1553$.

438

439 Mattei, C. Wortham H.and Quivet E., 2019. Heterogeneous degradation of pesticides by OH 440 radicals in the atmosphere: Influence of humidity and particle type on the kinetics, Science 441 of the Total Environment, 664, 1084-1094. 
443

444

445

446

447 Muñoz, A., Ródenas, M., Borrás, E., Vázquez, M., \& Vera, T. (2014). The gas-phase 448 degradation of chlorpyrifos and chlorpyrifos-oxon towards $\mathrm{OH}$ radical under atmospheric 449 450 451 453 454 455 456 457 458 Technol. 47, 6239-6246.

459

Meylan, W.M., Howard, P.H., 1993. Computer estimation of the Atmospheric gas-phase reaction rate of organic compounds with hydroxyl radicals and ozone. Chemosphere 26, 2293-2299. https://doi.org/10.1016/0045-6535(93)90355-9 conditions, Chemosphere 111, 522-528. http://doi.org/10.1016/j.chemosphere.2014.04.087

Palm, W.-U., Millet, M., Zetzsch, C., 1998. OH radical reactivity of pesticides adsorbed on aerosolmaterials: first results of experiments with filter samples. Ecotoxicol. Environ. Saf. 41, 36-43.

Pflieger, M., Monod, A., and Wortham, H., 2013. Heterogeneous Oxidation of Terbuthylazine by "Dark" OH Radicals under Simulated Atmospheric Conditions in a Flow Tube. Environ. Sci.

Sander, S.P., Friedl, R.R., D.M., Golden, Kurylo, M.G., Moortgat, G.K., Keller-Rudek, H., Wine, P.H., Ravishankara, A.R., Kolb, C.E., Molina, M.J., Finlayson-Pitts, B.J., Huie, R.E. and Orkin, V.L., 2006. Chemical kinetics and photochemical data for use in atmospheric studies. Evaluation number 15. JPL Publication. Jet Propulsion Laboratory, Pasedena 
465 Samir, B., Dégradation électrochimique du thiabendazole et l'imazalil. Etude de la réactibité 466 atmosphérique des composés aromatiques hétérocylciques azotés ", PhD, 18th of december 467 2018, ENSAT Agadir.

468

469 Scheyer, A., Morville, S., Mirabel, P., Millet, M. (2007). Variability of atmospheric pesticide 470 concentrations between urban and rural areas during intensive pesticide application, 41, 3604471 3618. http://doi.org/10.1016/j.atmosenv.2006.12.042

472

473 Segal-Rosenheimer, M., Linker, R., Dubowski, Y., 2011. Heterogeneous oxidation of the 474 insecticide cypermethrin as thin film and airborne particles by hydroxyl radical and ozone. 475 Phys. Chem. Chem. Phys. 13, 506-517. https://doi.org/10.1039/C0CP00931H

476

477 Sharma, K. K., \& Chibber, S., 1997. Photolysis of Diniconazole-M under Sunlight, Pesticide 478 Science, 49, 115-118.

479

480 Socorro, J., Gligorovski, S., Wortham, H., \& Quivet, E., 2015. Heterogeneous reactions of 481 ozone with commonly used pesticides adsorbed on silica particles. Atmospheric 482 Environment, 100, 66-73. http://doi.org/10.1016/j.atmosenv.2014.10.044 
484 Socorro, J., Durand, A., Temime-roussel, B., Gligorovski, S., Wortham, H., \& Quivet, E., 2016.

485 The persistence of pesticides in atmospheric particulate phase : An emerging air quality 486 issue. Nature Publishing Group, (August), 1-7.

487

488 Tomlin, C.D.S., 2000. The Pesticide Manual, twelfth ed. British Crop Protection Council, 489 Surrey, UK.

490

491 Vingarzan, R. A Review of Surface Ozone Background Levels and Trends. Atmos. Environ. $492 \quad 2004,38,3431-3442$

493

494 Xinzhong, Z., Yuechen, Z., Xinyi, C., Xinru, W., Huishan, S., \& Fengjian, L. (2018). Application 495 and enantiomeric residue determination of diniconazole in tea and grape and apple by 496 supercritical fluid chromatography coupled with quadrupole-time-of-flight mass 497 spectrometry. Journal of Chromatography A, 1581-1582, 144-155.

498

499 Yang, B., Meng, J., Zhang, Y., Liu, C., Gan, J., Shu, J., 2011. Experimental studies on the 500 heterogeneous reaction of NO3 radicals with suspended carbaryl particles. Atmos. Environ. 501 45, 2074-2079. https://doi.org/10.1016/j.atmosenv.2011.01.052 